\title{
PEMIKIRAN PENDIDIKAN MULLA SHADRA
}

\author{
Dahlan Lama Bawa ${ }^{1}$ \\ Pendidikan Agama Islam Fakultas Agama Islam| Unismuh Makassar
}

\begin{abstract}
ABSTRAK
Perkembangan pemikiran Islam di dunia semakin berkembang pesat. Salah satu tokoh yang sangat berpengaruh dalam pemikiran pendidikan Islah adalah Mullah Shadra. Shadr Al-Muta'allihin atau Mulla Shadra terkenal dengan pemikiran pendidikannya atau yang populer disebut filsafat Al-Hikmah Al Muta'aliyah (Filsafat Transendental). Jenis penelitian ini adalah penelitian pustakan, yaitu mengkaji tulisan-tulisan Mulla Shadra yang berkaitan dengan pemikiran pendidikan islam. Secara ontologis, pemikiran dan analisis Mulla Shadra didasarkan pada tiga hal, yaitu: Pertama, Ashalah al-wujud (prinsipianitas eksistensi) Seperti filosof-filosof muslim sebelumnya, Shadra berusaha menjawab masalah mahiyyah (kuiditas/esensi), dan wujud (eksistensi). Perbandingan antara eksistensi-esensi Shadra menyatakan eksistensi bersifat positif, pasti, tertentu dan nyata. Kedua, Tasykik (gradasi wujud) Jika para filosof peripatetik itu menganggap wujud setiap benda berbeda dari wujud yang lain, walaupun prinsipial dalam hubungannya dengan mahiyah, maka bagi Mulla Shadra wujud adalah realitas tunggal yang muncul dalam gradasi (tahap) yang berbeda. Ketiga, Gerak Substansial (al-harokhah al-jauhariyyah) Mulla Shadra berpendapat bahwa gerak tidak hanya terjadi pada empat kategori aksiden: kuantitas, kualitas, posisi dan tempat.
\end{abstract}

\section{Kata Kunci: Pemikiran, Pendidikan}

\begin{abstract}
The development of Islamic thought in the world is growing rapidly. One Of the influential figures hearts Islam Education Thought was Mullah Sadra. Shadr AlMuta'allihin atau Mulla Shadra thought education or a popular use is called the philosophy of Al-Hikmah Al muta'aliyah (transcendental philosophy). Type of this research is library research., assess namely writings relates with Mulla Sadra thought Islamic Education Operates ontological, Mulla Sadra Thought and analysis is based on three things are: First, Ashalah al-being (prinsipianitas Existence) Like the earlier Muslim philosophers, Sadra tried Answering problems mahiyyah (kuiditas / essence), and forms (Existence). comparison between Existence essence Sadra states are positive, certainly, Specific and Realistic. Second, Tasykik (gradation form) IF IT Peripatetic philosopher considers form Benda any different of another form, although prinsipial hearts conjunction with mahiyah, Then For Mulla Sadra form is sole Reality Appears hearts gradation (Phase) the differentiate. Third, substantial motion (al-harokhah al-jauhariyyah) Mulla Sadra argued that the motion does not only happen in the four categories of accidents: quantity, quality, position and place.
\end{abstract}

\section{Keywords: Development, Education}




\section{PENDAHULUAN}

Dunia Islam ingin ditelusuri dan ditela'ah oleh pemikiran dan karya-karya para tokoh, dengan maksud menambah khazanah pengetahuan hingga untuk kajian dan studi analisis perbandingan, maka salah satunya adalah Muhammad ibn Ibrahim Yahya Qowami Syirazi, yang dikenal dengan nama Shadr Al-Din Syirazi atau Mulla Shadra, dilahirkan di Syiraz pada 979 H/1571 M dari keluarga Qawam yang terkenal dan terhormat. Ayahnya dikenal sebagai seorang penasehat raja dan bekerja sebagai ahli hukum Islam dipemerintahan Syafawi tepatnya di Provinsi Fars.

Shadr Al-Muta'allihin atau Mulla Shadra terkenal dengan pemikiran pendidikannya atau yang populer disebut filsafat Al-Hikmah Al Muta'aliyah (Filsafat Transendental). Penamaan itu dipakai sebagai sinonim dari islilah filsafat Tertinggi (Al-Hikmah Al-Ulya), lawan dari matematika dan fisika, dalam klasifikasi filsafat tradisional. Pemikiran yang digeluti oleh Mulla Shadra adalah persoalan metafisika yang didasari oleh pertanyaan tentang keberadaan Tuhan. yakni menggunakan argumen rasional.

Seusai menamatkan pendidikan dasarnya di Syiraz, dia berangkat menuju Isfahan yang pada waktu itu menjadi pusat pemerintahan dan pusat intelektual Persia. Di sana dia bertemu dengan guru-guru terkenal pada waktu itu. Dia belajar ilmu-ilmu agama (naqli) pada Syaikh Baha' Al-Din Al'Amili dan belajar ilmu-ilmu rasional (aqli) filsafat dan logika pada Mir Damad. Keduanya merupakan pelopor utama madzhab Isfahan. Dia dipercaya oleh Gubernur Fars, Allahwardi Khan, untuk memimpin sebuah sekolah yang akhirnya sekolah tersebut menjadi pusat studi yang berpengaruh di Persia. Mulla Sadra meninggal pada usia 79 tahun di Basrah, sepulangnya dari menunaikan ibadah haji yang ketujuh kalinya.

Secara ontologis, pemikiran dan analisis Mulla Shadra didasarkan pada tiga hal, yaitu: Pertama, Ashalah alwujud (prinsipianitas eksistensi) Seperti filosof-filosof muslim sebelumnya, Shadra berusaha menjawab masalah mahiyyah (kuiditas/esensi), dan wujud (eksistensi). Perbandingan antara eksistensi-esensi Shadra menyatakan eksistensi bersifat positif, pasti, tertentu dan nyata. Kedua, Tasykik (gradasi wujud) Jika para filosof peripatetik itu menganggap wujud setiap benda berbeda dari wujud yang lain, walaupun prinsipial dalam hubungannya dengan mahiyah, maka bagi Mulla Shadra wujud adalah realitas tunggal yang muncul dalam gradasi (tahap) yang berbeda. Ketiga, Gerak Substansial (al-harokhah al-jauhariyyah)Mulla Shadra berpendapat bahwa gerak tidak hanya terjadi pada empat kategori aksiden: kuantitas, kualitas, posisi dan tempat. Akan tetapi gerak juga terjadi pada substansi.

\section{METODE PENELITIAN}

\begin{tabular}{llr}
\multicolumn{1}{c}{ Jenis } & \multicolumn{2}{c}{ penelitian ini adalah } \\
penelitian yang bersifat kajian \\
kepustakaan $($ Library Researce) & yang \\
difokuskan pada penelusuran dan \\
penelaan literature serta bahan pustaka \\
yang dianggap ada kaitannya dengan \\
pemikiran Pendidikan Mulla Shadra.
\end{tabular}


Sumber data dalam penelitian ini ada dua yaitu data primer dan data sekunder. Data primer adalah berupa buku-buku yang secara khusus membahas tentang pluralisme agama dan pendidikan Islam. Sedangkan Data sekunder adalah referensi atau bukubuku yang dapat mendukung permasalahan pokok yang dibahas.

Teknik pengelolaaan data yaitu data yang dihimpun melalui riset kepustakaan semua data bersifat kualitif, yaitu pengungkapan data melalui deskripsi (pemaparan), sehingga dalam pengelolaannya yaitu mengadakan dan mengemukakan sifat data yang diperoleh kemudian dianalisa lebih lanjut guna mendapatkan kesimpulan. Adapaun analisis data. pada tahap ini, ada tiga tahap yang dilalui dalam penelitian ini, yaitu: reduksi data (data reduction), penyajian data (data display), dan penarikan kesimpulan (conclusion drawing).

\section{HASIL DAN PEMBAHASAN}

\section{Pemikiran Mulla Shadra}

Mulla Shadra termasuk kategori tokoh pemikir Islam metafisik yang karya-karyanya sangat monumental dalam bentuk mazhab, Menurut M.M. Syarif dalam History of Muslim Philosophy mengemukan bahwa Mulla Shadra disebut-sebut sebagai pendiri mazhab ketiga yang utama. Mazhab utama pertama adalah mazhab Peripatetik dengan eksponen terbesarnya dalam dunia Islam adalah Ibnu Sina, yang lainnya adalah mazhab Illuminatif (al-hikmah al-isyraqiyah/al-khalidah) yang dibangun oleh Suhrawardi alMaqtul. Mulla Shadra juga mengadopsi prinsip-prinsip tertentu dari masingmasing mazhab, seperti hylomorphism dari Peripatetik, gradasi wujud dan polapola surga (celesticalarchetyupes) dari mazhab illuminasi. Bahkan ia mengadopsi prinsip-prinsip tertentu dari ajaran-ajaran sufi Ibnu Sina. Keselarasan dan keteraturan substansi dunia yang sebelumnya tidak pernah nampak sebagai prinsip beberap mazhab hikmat, dan tidak pernah dibangun secara sistemik dalam bahasa yang logis oleh hikmawan sebelum Mulla Shadra. Oleh karenanya, layak disebut sebagai pendiri hikmah yang orisinil dan relatif baru dalam pergumulan filsafat Muslim dengan al-Hikmah al-Muta'alliyah-nya.

Hal pertama yang digeluti oleh Mulla Shadra adalah persoalan metafisika yang didasari oleh pertanyaan tentang keberadaan Tuhan. Persoalan esensi dan eksistensi menjadi tema sentral dalam uraian filsafatnya. Filsafat Mulla Shadra dinilai mampu mempertemukan beberapa aliran filsafat yang berkembang sebelum Mulla Shadra. Aliran-aliran itu secara umum dikelompokkan menjadi: 1) Aliran paripatetik, 2) Filsafat iluminasionis, 3) Irfan (mistisismeislam), dan 4) kalam (teologi). Pergelutan Mulla Shadra dengan esensi dan eksistensi Allah melahirkan sebuah system filsafat yang tertata. Shadra menggunakan istilah alHikmah al-Muta'aliyyah (filsafat transendental) yang merupakan sinonim dari istilah filsafat tertinggi atau lebih dikenal dengan filsafat hikmah.

Salah satu bentuk pemikiran pendidikan Mulla Shadra adalah Failsafat hikmah, yaitu kebijaksanaan yang diperoleh lewat pencerahan spiritual atau intuisi intelektual dan 
disajikan dalam bentuk yang rasional, yakni menggunakan argumen rasional. Secara ontologis, hikmah didasarkan pada tiga hal:

\section{Ashalah al-wujud (Prinsipianitas Eksistensi).}

Seperti filosof-filosof muslim sebelumnya, sadra berusaha menjawab masalah mahiyyah (kuiditas/esensi), dan wujud (eksistensi). Perbandingan antara eksistensi-esensi sadra menyatakan eksistensi bersifat positif, pasti, tertentu dan nyata. Sedangkan esensi bersifat samar, gelap, tidak tertentu, negative, dan tidak nyata. Esensi tidak memiliki dirinya sendiri dan apapun yang ada pada-Nya adalah karena hubungan dengan eksistensi, sedang eksistensi bersifat nyata berkat manivestasi dan hubungannya dengan eksistensi mutlak, yakni Tuhan.

Bagi Shadra, Tuhan adalah wujud mutlak dan apa yang disebut sebagai akal terpisah oleh para filosof atau ide-ide tetap (a'yan al-tsabithah oleh Ibnu Arabi, tidak mempunyai wujud eksternal tetapi hanya merupakan kandungan dalam fikiran Tuhan, yakni ide-idenya. Selanjutnya jenis-jenis wujud atau eksistensi ini memperlihatkan karakteristik esensial tertentu dalam fikiran. Ini persis dengan matahari yang sebagai sumber cahaya, identik dengan cahaya yang dipancarkan, tetapi cahaya tersebut bisa memunculkan karakteristik yang berbeda seperti yang tampak dalam prisma.

\section{Tasykik (Gradasi Wujud)}

Jika para filosof peripatetik itu menganggap wujud setiap benda berbeda dari wujud yang lain, walaupun prinsipial dalam hubungannya dengan mahiyah, maka bagi Mulla Shadra wujud adalah realitas tunggal yang muncul dalam gradasi (tahap) yang berbeda. Meminjam dari Suhrawardi, kita dapat membandingkan berbagai wujud cahaya. Ada cahaya matahari, ada cahaya lampu, ada cahaya lain. Semuanya cahaya, tetapi dengan predikat yang berbeda artinya. Begitu pula, ada Tuhan, ada manusia, ada binatang, ada batu. Semuanya satu wujud, satu realitas, tetapi dengan berbagai tingkat intensitas dan manifestasi.

Gradasi ini bukan pada mahiyah, tetapi pada wujud, bukan pada kuiditas, tetapi pada eksistensi. Tahap paling tinggi dalam hierarki wujud ini adalah Tuhan yang Maha Tinggi dan tahap yang paling rendah adalah Materi Awal, yang menjadi bahan segala bahan (maddah al mawadd atauhayula).

\section{Gerak Substansial (al-harokhah al-jauhariyyah)}

Mulla Shadra berpendapat bahwa gerak tidak hanya terjadi pada empat kategori aksiden yaitu kuantitas, kualitas, posisi dan tempat. Akan tetapi gerak juga terjadi pada substansi. Kita melihat dalam dunia eksternal perubahan benda material dari keadaan yang satu ke keadaan yang lain. Buah apel berubah dari hijau, kemudian kuning, kemudian merah. Ukuran, rasa, berat juga selalu mengalami perubahan. Karena keberadaan aksiden bergantung pada keberadaan substansi, maka perubahan aksiden terkait dengan perubahan substansi juga. Semua benda material berubah. Dalam hubungan ini Shadra mempertahankan sifat huduts (kebaharuan) dunia fisik, sifat tidak 
permanen dari esensi materi, dan waktu sebagai dimensi materi keempat (yakni, sebagai satuan ukuran kuantitas gerak).

Mulla Shadra menyebut filsafatnya sebagai Al-Hikmah Al Muta'aliyah (Filsafat Transendental). Penamaan itu dipakai sebagai sinonim dari islilah filsafat tertinggi (Al-Hikmah Al-Ulya), lawan dari matematika dan fisika, dalam klasifikasi filsafat tradisional. Dengan begitu, Al-Hikmah Al-Muta'aliyah sama persis dengan filsafat pertama yang tak lain adalah filsafat umum. Selain itu $\mathrm{Al}$ Hikmah Muta'aliyah adalah mazhab pemikirannya dalam metafisika. Urutan dalam hal pembahasan yang mendasari Al-Hikmah Al Muta'aliyah meliputi hakikat kemendasaran eksistensi (ashalah al-wujud).dan Kemanunggalan wujud (wahdad al-wujud). Membahas prinsip mengenai eksistensi dan esensi.

Sehubungan dengan hal tersebut, para logikawan telah memaparkan dua jenis keniscayaan esensial, yaakni keniscayaan esensial sementara. Sebagai contoh, apabila kita katakan bahwa esensi manusia adalah "hewan rasional" (atau esensi "empat" adalah "bilangan genap"), maknanya adalah bahwa eksistensi manusia terkait langsung dengan esensi kehewanan dan rasionalitasnya. Oleh karena itu, tanpa rasionalitas pasti tidak ada manusia. Sedangkan dalam keniscayaan abadi, hanya milik Allah. Hal ini sejalan dengan kajian tentang kekuasaan Allah yang bersifat mutlak.

Tela'ah tentang hakikat kausalitas dan watak hubungan sebabakibat, peneguhan hubungan akibat pada sebab sebagai hubungan iluminatif, dan pengakuan adanya efek kemaujudan (ontic/watak) sebagai "manifestasi" (tajali wa tasya'un) Contohnya, seorang ayah dan anak adalah dua maujud. Yang pertama merupakan sumber bagi yang kedua, dalam arti bahwa anak berasal dari ayah. Lalu terjadilah suatu hubungan diantara keduanya sebagai hakikat ayah atau anak. Pengukuhan gerakan subtansial (al-harakah aljauhariyyah), semua maujud alami dapat berubah karena kodrat alam itu sendiri adalah potensi dan kesiapan. Perubahan bersifat seketika dan bertahap seiring dengan perputaran waktu disebut dengan "gerak" (harakah)

\section{KESIMPULAN}

1. Muhammad ibn Ibrahim Yahya Qowami Syirazi, yang dikenal dengan nama Shadr Al-Din Syirazi atau Mulla Shadra, dilahirkan di Syiraz pada 979 H/1571 M dari keluarga Qawam yang terkenal dan terhormat. Ayahnya dikenal sebagai seorang penasehat raja dan bekerja sebagai

2. ahli hukum islam dipemerintahan Syafawi tepatnya di Provinsi Fars.

3. Pemikiran Mulla Shadra yang dituangkan dalam bentuk karya terbesar sekaligus merupakan karya yang monumntal adalah al-Hikmah al-Muta'aliyah fi al-Asrar alAqliyah al-Arba'ah (Hikmah Agung tentang Empat Perjalanan Akal)

4. Filsafat Hikmah Mulla Shadra mampu mempertemukan beberapa aliran filsafat yang berkembang sebelum Mulla Sadra. Seperti Aliran Irfan (mistisisme Islam) dan kalam (Teologi),. filsafatnya sebagai $A l$ Hikmah Al Muta'aliyah (Filsafat Transendental) merupakan suatu 
sistem filsafat yang koheren meskipun menggabungkan berbagai mazhab filosofis sebelumnya. Dengan berlandaskan pada pokok utama kajian pemikiran Mulla Shadra yakni metafisika.

\section{DAFTAR PUSTAKA}

Bagir, Haidar. 2005.Buku Saku Filsafat Islam. Bandung: Mizan

Fakhry, Majid. 2001. Sejarah Filsafat Islam: Sebuah Peta Kronologis. Bandung: Mizan

Muthahhari, Murtadha. 2002. Filsafat Hikmah:Pengantar Pemikiran Sadra. Bandung; Mizan.

Shadra, Mulla. 2001. Kearifan Puncak (Hikmah al-Arsyiah). Yogyakarta: Pustaka Pelajar .http://makalahmajannaii.blogspot. com/2012/04/mulla-sadra-alhikmah-al-mutaaliyah.html

http://neysya-atidiri.blogspot.com /2012/01/pemikiran-filsafat-islammulla-shadra_22.html

.http://neysya-jatidiri.blogspot. com/2012/01/pemikiran-filsafatislam-mulla-shadra_22.html 